\title{
Anti-lock Brake System
}

\section{Lilik Budiyarto}

Mahasiswa Program Studi Mesin Otomotif,

Fakultas Teknik, Universitas Muhammadiyah Magelang

Email: lilikbudiyarto@gmail.com

\section{Ringkasan}

ABS merupakan sebuah sistem pengereman yang menghentikan kendaraan dengan mempertahankan keadaan roda tidak terkunci sehingga kendaraan tetap dapat dikendalikan dengan mudah. Sistem ini bekerja pada sebagian besar jenis permukaan jalan dan mengurangi resiko kecelakaan. Beberapa penelitian telah menunjukkan, bahwa ABS dapat menurunkan kemungkinan kecelakaan kendaraan sebesar $18 \%$.

\section{Pendahuluan}

Berdasar data yang diungkap oleh Korps Lalu Lintas Kepolisian Republik Indonesia (Korlantas Polri), kecelakaan lalu lintas yang terjadi selama 2018 berdasarkan kondisi kendaraan, penyebab terbesar karena gagalnya pengereman. Jumlah kejadiannya bahkan mengalami kenaikan 32 persen. Pada 2017 lalu, jumlah kecelakaan karena rem rusak ada sebanyak 7.083 kejadian. Sementara sepanjang tahun 2018 lalu, angkanya mengembang menjadi 9.333 tragedi.

Jumlah tersebut bukan angka yang sedikit, bila dibagi total hari dalam satu tahun, setidaknya ada 25 kejadian kecelakaan per hari di seluruh Indonesia karena rem kendaraan rusak, baik itu mobil ataupun motor [1]. Upaya pengurangan terhadap kecelakaan lalu-lintas saat ini telah banyak dilakukan. Teknologi sistem pengereman menjadi salah satu teknologi yang dikembangkan untuk mengendalikan kecelakaan lalu-lintas [2]. Untuk mengurangi angka kecelakan akibat rem rusak tersebut kemudian para perusahaan ttomotif mengembang rem Antilock Brake Sistem (ABS). ABS merupakan sebuah sistem pengereman yang menghentikan kendaraan dengan mempertahankan keadaan roda tidak terkunci sehingga kendaraan tetap dapat dikendalikan dengan mudah. Sistem ini bekerja pada sebagian besar jenis permukaan jalan dan mengurangi resiko kecelakaan. Beberapa penelitian telah menunjukkan, bahwa ABS dapat menurunkan kemungkinan kecelakaan kendaraan sebesar 18\%. Saat ini pengembangan dari sistem rem ABS sudah berada pada pengaturan berupa sinyal dari sensor kecepatan angular roda yang diteruskan ke modul yang digunakan untuk mengatur kecepatan pompa menggerakan katup-katup yang bekerja memotong tekanan konstan dari master silinder ke master kaliper.

ABS ini diciptakan agar roda kendaraan tidak akan terkunci saat melakukan pengereman, kendaraan mudah dikendalikan saat mengerem secara mendadak. Pengereman denagn ABS lebih cepat dibanding dengan rem biasa, pengereman semakin efektif dan tentunya mengurangi tingkat kecelakaan [3].

\section{Bagian-bagian ABS}

ABS memiliki empat komponen utama yang saling terkait satu sama lain. Keempat komponen ini memiliki fungsi yang berbeda-beda, kompenen tersebut antara lain:

a. Sensor kecepatan

Sensor ini berfungsi untuk membaca kecepatan putaran roda, terdapat di setiap roda atapun di diferensial (tergantung dari pabrik).

b. Katup rem

Di setiap jalur minyak rem terdapat katup, dan katup ini dikendalikan oleh komputer / kontroler ABS. Secara umum, katup rem memiliki tiga posisi yang berbeda. Katup posisi satu: Dalam posisi ini, katup dalam posisi terbuka penuh, sehingga tekanan minyak rem secara penuh langsung diteruskan ke rem. Katup posisi dua: Dalam posisi ini, katup akan 
menghalangi tekanan minyak rem, sehingga tekanan tidak akan diteruskan ke rem walaupun pengemudi menekan rem. Katup posisi tiga: Dalam posisi ini, katup akan menghalangi sebagian dari tekanan minyak rem, sehingga tekanan hanya setengah yang diteruskan ke rem, walaupun pengemudi menekan rem secara penuh.

c. Pompa

Fungsi dari pompa ini adalah mengembalikan tekanan pada jalur pengereman yang dilepaskan oleh katup ke rem.

d. Kontroler / Komputer

Fungsi dari alat ini adalah otak yang mengendalikan katup dan mengolah data dari sensor kecepatan. Sensor kecepatan akan membaca kecepatan mobil setiap saat, dan menyampaikan data kecepatan tersebut ke pada kontroler. Untuk mobil berhenti secara normal di kecepatan $100 \mathrm{~km} / \mathrm{jam}$, akan diperlukan waktu selama 5 detik. Tentunya pada saat anda melakukan pengereman normal, tidak akan terjadi penguncian roda kendaraan [4].
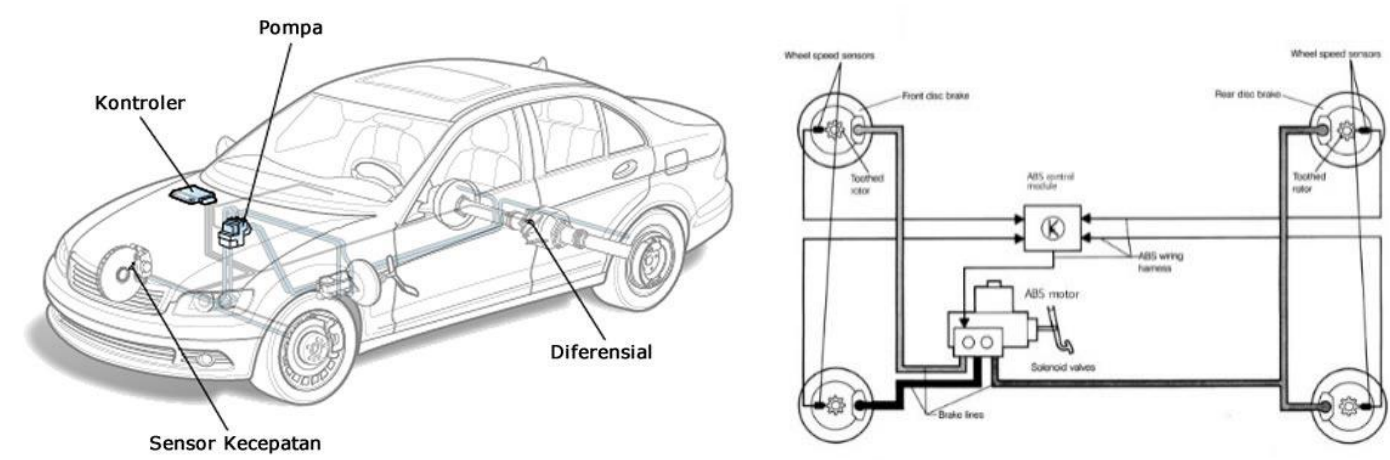

Gambar 1. Komponen utama ABS [5]

\section{Cara kerja ABS}

Sensor kecepatan akan membaca kecepatan mobil setiap saat, dan menyampaikan data kecepatan tersebut ke pada kontroler. Untuk mobil berhenti secara normal di kecepatan 100 $\mathrm{km} / \mathrm{jam}$, akan diperlukan waktu selama 5 detik. Tentunya pada saat anda melakukan pengereman normal, tidak akan terjadi penguncian roda kendaraan. Lain ceritanya jika anda melakukan pengereman mendadak, maka roda akan terkunci. Waktu yang diperlukan untuk roda terkunci kurang lebih 1 detik.

Karena kontroler telah diprogram, untuk dapat menghentikan kendaraan secara maksimal, terkuncinya roda saat pengereman tidak boleh terjadi. Sebelum roda terkunci, kontroler akan mendapatkan data dari sensor kecepatan dan akan memerintahkan katup mengurangi tekanan, dengan cara mengambil katup posisi dua atau katup posisi tiga, sesuai perintah dari kontroler. Setelah putaran roda terdeteksi oleh sensor kecepatan, kontroler akan memerintahkan katup untuk mengambil posisi satu, yang membuat tekanan minyak rem kembali dan diteruskan ke rem. Cara kerja rem ABS tersebut terjadi sangat cepat, rata-rata sistem ABS pada mobil sekarang, mampu melakukan 15 kali proses tersebut dalam 1 detik.

Secara sederhana sistem ABS adalah fitur keselamatan yang membuat rem tidak terkunci jika dilakukan pengereman mendadak, hal ini berkat adanya sensor yang dipasangkan pada roda sehingga mampu mendeteksi apabila putaran roda terhenti saat sedang berjalan. Adapun sensor tersebut terhubung dengan komputer yang diteruskan dengan mengatur tekanan agar kinerja Teknologi ABS bisa maksimal. Berikut ini kelebihan dan kekurang dari sistem pengereman $\mathrm{ABS}$. 
Kelebihan sistem Rem ABS:

- Rem sangat pakem dan meyakinkan jika kendaraan berjalan dipermukaan yang datar, atau diatas aspal,

- Roda kendaraan tidak akan terkunci saat melakukan pengereman,

- Kendaraan mudah dikendalikan saat mengerem secara mendadak,

- Pengereman Rem ABS lebih cepat dibanding dengan rem biasa, dan

- Pengereman semakin efektif dan tentunya tingkat kecelakaan semakin kecil.

Kekurangan sistem Rem ABS:

- Kendaraan sulit berhenti jika mengerem dijalan yang berkerilkil atau tidak rata, jadi kendaraan sulit untuk berhenti secara optimal,

- Saat Rem basah atau jalan dijalan yang tidak rata, rem menjadi tidak pakem dan kadang berbunyi menggeruk,

- Rem ABS dapat bekerja optimal jika kendaraan melewati jalan yang beraspal atau jalan yang rata, dan

- Mobil sulit digunakan untuk freestyle, misalnya Stoppi.

\section{Kesimpulan}

Kontrol ABS adalah masalah kontrol yang non linier dengan hubungan yang rumit antara komponen-komponennya. Penelitian yang telah dilakukan di sistem kontrol ABS mencakup berbagai masalah dan tantangan. Banyak metode kontrol berbeda untuk ABS telah dikembangkan dan penelitian tentang peningkatan kontrol metode terus berlanjut. Sebagian besar pendekatan ini membutuhkan model sistem, dan beberapa di antaranya tidak dapat mencapai kinerja yang memuaskan di bawah perubahan berbagai kondisi jalan. Sedangkan metode komputerisasi lunak seperti Fuzzy kontrol tidak memerlukan model yang tepat.

\section{Referensi}

[1] D. Halim, “Jumlah Kecelakaan Lalu Lintas hingga 7 Juni 2019,” kompas.com, 2019. [Online]. Available: https://nasional.kompas.com/read/2019/06/08/15245501/jumlahkecelakaan-lalu-lintas-hingga-7-juni-2019. [Accessed: 08-Jan-2019].

[2] F. Hanif, S. Munahar, and D. S. Putra, "Pengembangan Sirkuit Security System u ntuk Meningkatkan Driver Behaviour Control pada Kendaraan," Automotive Experiences, vol. 1, no. 1, pp. 13-19, 2018.

[3] Y. P. Imandiar, “Apakah ABS Efektif Selamatkan Pengendara dari Celaka?," Tirto.id, 2018. [Online]. Available: https://tirto.id/apakah-abs-efektif-selamatkan-pengendaradari-celaka-dagE. [Accessed: 08-Feb-2019].

[4] Fanny Jayadi, "Anti-lock braking system [ABS]," docplayer, 2017. [Online]. Available: https://docplayer.info/38056340-Anti-lock-braking-system-abs.html. [Accessed: 08-Feb-2019].

[5] G. F. Mauer, "A fuzzy logic controller for an ABS braking system," IEEE Transactions on Fuzzy Systems, vol. 3, no. 4, pp. 381-388, 1995. 